\title{
Photovoltaic Partner Selection for High-efficiency Photovoltaic-electrolytic Water Splitting Systems: Brief Review and Perspective
}

\section{DUY PHONG PHAM ( $\sim$ phamphong280783@gmail.com )}

Sungkyunkwan University - Suwon Campus https://orcid.org/0000-0002-0512-4665

\section{Sunhwa Lee}

Sungkyunkwan University

Junsin Yi

Sungkyunkwan University

\section{Short Report}

Keywords: Solar to hydrogen production, Electrolytic water splitting, III-V tandem solar cells, III-V triplejunction solar cells, Photovoltaic-electrolysis water splitting

Posted Date: March 16th, 2021

DOl: https://doi.org/10.21203/rs.3.rs-276993/v1

License: (a) (1) This work is licensed under a Creative Commons Attribution 4.0 International License. Read Full License

Version of Record: A version of this preprint was published at Silicon on July 6th, 2021. See the published version at https://doi.org/10.1007/s12633-021-01220-2. 


\title{
Photovoltaic partner selection for high-efficiency photovoltaic- electrolytic water splitting systems: brief review and perspective
}

\author{
Duy Phong Pham*, Sunhwa Lee and Junsin Yi* \\ College of Information and Communication Engineering, Sungkyunkwan University, Gyeong-do \\ 16419, Suwon 440-746, Republic of Korea
}

*Corresponding authors: Junsin Yi and Duy Phong Pham

Email: junsin@skku.edu; pdphong@skku.edu 


\begin{abstract}
Photovoltaic-electrolysis water splitting (PV-EWS) is the most promising approach for high solarto-hydrogen (STH) efficiency. The present PV-EWS systems achieve the highest STH performance by using a III-V triple-junction configuration, which, however, involves a complex and expensive manufacture process. Therefore, in this work, we demonstrate a III-V double junction device that can be used as an alternative to the III-V triple-junction device for high STH conversion efficiency of the PV-EWS systems. We estimate the STH performance via coupling world-recorded multi-junction photovoltaic (PV) and our experimented cell configurations with an EWS system. The results show that the III-V double junction, owing to the good trade-off between the efficiency loss and compensation, exhibits a higher STH efficiency than the III-V triple-junction. Furthermore, strategies for improving the efficiency of the III-V double junction device for low-cost PV-EWS system are discussed.
\end{abstract}

Keywords: Solar to hydrogen production; Electrolytic water splitting; III-V tandem solar cells; III-V triple-junction solar cells; Photovoltaic-electrolysis water splitting. 


\section{Introduction}

Solar-to-hydrogen (STH) production via electrolysis water splitting (EWS) holds promise as a strategy for utilizing thoroughly renewable and sustainable solar energy sources, and convert these into storable and transportable energy sources without releasing harmful byproducts such as the $\mathrm{CO}_{2}$ gas [1-3]. Diverse configurations of the EWS systems, which are based on photocatalysts and/or solar cells have been popularly suggested, such as photocatalytic, photoelectrochemical (PEC), and photovoltaic-electrolysis water splitting (PV-EWS) configurations [4]. However, the main challenge for STH production continues to be the significantly higher manufacture cost compared with the $\mathrm{H}_{2}$ gas produced from the traditional fossil fuel: for example, the $\mathrm{H}_{2}$ threshold cost according to the calculation by the United States Department of Energy has been $\$ 2.00$ to $\$ 4.00$ per gallon of gasoline equivalent [5], whereas the up-to-date production cost of $\mathrm{H}_{2}$ from electrolysis is up to $\$ 3.26$ to $\$ 6.62$ per gallon of gasoline equivalent [6]. Therefore, numerous efforts have been focused on further enhancing the STH conversion performance using simply established EWS configurations for a cost-effective manufacture process. For example, some efforts that focused on improving the Si-based photocathodes achieved an STH conversion efficiency of $11.5 \%$ [7-13]. Table 1 summarizes briefly recent results related to these efforts. Others, which were devoted to wireless monolithic solar water splitting, exhibited simplicity and hence, cost-effectiveness $[3,14,15]$. Further efforts were dedicated to improving the power conversion efficiency (PCE) of the PV devices [16-18]. Some impressive results have been summarized in Table 2 [16, 18-24]. To date, the highest recorded efficiency of the state-of-the-art photocatalysts and PEC systems is 5\% [25] and 12.4\% [26, 27], respectively. However, the most recent impressive efficiencies of $30 \%$ [19] and 24.4\% [20] STH conversion were achieved by the PV-EWS systems, which were based on concentrator PV modules using III-V triple-junction solar 
cells directly connected with polymer electrolyte electrochemical cells. Although electricityconversed PV devices and PV-EWS systems based on a III-V triple-junction configuration have achieved a world-record efficiency of $37.9 \%$ [28] and $30 \%$ [19], respectively, their complex manufacture process and high material cost limits the industrial applications of this configuration to specific fields such as aerospace.

Owing to its relatively simpler manufacture technology, the III-V double junction device is more commercially cost-effective than the III-V triple-junction device. Moreover, the former can generate a high open-circuit voltage in the range of $2-2.5 \mathrm{~V}$, which can sufficiently fulfil the practical minimum photo-voltage requirement of the EWS systems (which is normally $\geq 1.5 \mathrm{~V}$ ) [23]. This $\mathrm{V}_{\mathrm{oc}}$ threshold of the III-V double junction device is as insignificant as that of the III-V triple-junction cells (which is normally in the range of $2.5-3.5 \mathrm{~V}$ ) compared with the practical minimum required voltage $(1.5 \mathrm{~V})$ of the EWS systems; this limits the energy losses in the EWS process $[23,29]$. However, despite the apparent cost-effectiveness, the capability of the III-V double junction cells to produce a high PV-EWS efficiency as that currently achieved by the IIIV triple-junction cells remains unestablished. Table 2 presents some recent reports, which show that an efficiency as high as $18 \%$ was achieved by the PV-EWS system using a III-V double junction device. Owing to the recent persistent advantages of the light concentrator and manufacture technologies, the III-V double junction device is predicted to be competitive with the silicon PV in terms of efficiency and cost in certain applications [23].

Coupling the III-V triple-junction and double junction PV configurations separately with an EWS system, we demonstrated that the III-V double junction devices can achieve higher STH conversion performance, which indicates that despite their currently lower PCE, they hold promise 
as an alternative to the III-V triple-junction devices for high PV-EWS efficiency. Furthermore, we estimated and compared the STH conversion performance of a PV-EWS system based on the recently world-recorded cells with those of the laboratory-experimented cells (i.e., the III-V tripleand double-junction devices). We also compared the STH conversion performance of the III-V materials with that of the Si-based materials: the results indicated that the former are appropriate for high-efficiency and low-cost PV-EWS systems, owing to the good trade-off between energy loss and compensation. Moreover, the recent and persistent developments in the III-V device technology allow considerable room for further enhancement in the PV-EWS system performance.

\section{Experiment}

Si-based multijunction devices including hydrogenated amorphous Si (a-Si:H) / hydrogenated nanocrystalline Si (nc-Si:H) double junction, and a-Si:H / Si heterojunction (SHJ) double junction solar cells were prepared by the plasma-enhanced chemical vapor deposition method. The a-Si:H / nc-Si:H double junction device was implemented on a fluorine-doped tin oxide (FTO) glass substrate with an a-Si:H top and nc-Si:H bottom cell configuration. Silane $\left(\mathrm{SiH}_{4}\right)$ and $\mathrm{H}_{2}$ gases were used as precursors for the intrinsic absorption layers, and diborane $\left(\mathrm{B}_{2} \mathrm{H}_{6}\right)$ and phosphine $\left(\mathrm{PH}_{3}\right)$ gases were used as doping precursors for the p-type and n-type layers, respectively. In the a-Si:H / SHJ double junction, the a-Si:H top cell was directly deposited on the SHJ bottom cell, which functions as a substrate. In the III-V double junction and triple devices, the cells were implemented by the metal organic chemical vapor deposition (MOCVD) method: for the III-V double junction configuration, the p-type GaAs materials with (001) orientation were used as a substrate for the like-epitaxy MOCVD growth process of sequential layers, while for the III-V triple-junction configuration, p-type Ge material was used as a substrate. The cross-sections of all 
multijunction cell configurations are illustrated in Fig. 1: All cells are characterized by the I-V curves measured under the standard illumination of one-sun (AM 1.5). These curves were used to extract the cell parameters, namely the open circuit voltage $\left(\mathrm{V}_{\mathrm{oc}}\right)$, short-circuit current density $\left(\mathrm{J}_{\mathrm{sc}}\right)$, fill factor $(\mathrm{FF})$, efficiency $\left(\mathrm{E}_{\mathrm{ff}}\right)$, maximum power point $\left(\mathrm{P}_{\mathrm{MPP}}\right)$, voltage at maximum power point ( $\left.\mathrm{V}_{\mathrm{MMP}}\right)$, and current density at maximum power point ( $\left.\mathrm{J}_{\mathrm{MMP}}\right)$.

\section{Result and discussion}

The STH conversion efficiency $(\eta)$ based on EWS is generally defined by the thermodynamic potential of $1.23 \mathrm{~V}$, current density of the EWS $\left(\mathrm{J}_{\mathrm{WS}}\right)$, the Faradaic efficiency $\left(\eta_{\mathrm{FE}}\right)$, and the incident irradiance power or input power $\left(\mathrm{P}_{\mathrm{in}}\right)$, as expressed in the following relation:

$\eta=\left(1.23 \mathrm{~V} . \mathrm{J}_{\mathrm{WS}} . \eta_{\mathrm{FE}}\right) / \mathrm{P}_{\mathrm{in}}$

Generally, in a PV-EWS system, the $\mathrm{P}_{\text {in }}$ is provided by the PV device system and therefore, $\mathrm{P}_{\text {in }}$ nearly corresponds to the power input of the system. The relation between $\mathrm{P}_{\text {in }}$ and PCE of the PV device system is well-known and defined as follows:

$$
\mathrm{PCE}=\mathrm{P}_{\max } / \mathrm{P}_{\text {in }}=\left(\mathrm{J}_{\mathrm{sc}} \cdot \mathrm{V}_{\mathrm{oc}} . \mathrm{FF}\right) / \mathrm{P}_{\text {in }}
$$

where, $\mathrm{J}_{\mathrm{sc}}$ is the short-circuit current density, $\mathrm{V}_{\mathrm{oc}}$ is the open-circuit voltage, and FF is the fill factor.

Using equation (2), the value of $\eta$ in equation (1) can be rewritten as a function of PCE and the cell parameters, as follows:

$\eta=\left(1.23 \mathrm{~V} . \mathrm{J}_{\mathrm{WS}} . \eta_{\mathrm{FE}} . \mathrm{PCE}\right) /\left(\mathrm{J}_{\mathrm{sc}} . \mathrm{V}_{\mathrm{oc}} . \mathrm{FF}\right)$ 
Under ideal operation conditions, assuming maximum electrolysis efficiency, the PV-EWS system can operate under short-circuit conditions. This means that $\mathrm{J}_{\mathrm{WS}}$ is nearly equal to $\mathrm{J}_{\mathrm{sc}}$ and $\eta_{\mathrm{FE}}$ is $100 \%$. Therefore, equation (3) can be simplified and rewritten as follows:

$\eta=(1.23 \mathrm{~V} . \mathrm{PCE}) /\left(\mathrm{V}_{\mathrm{oc}} . \mathrm{FF}\right)$

Herein, if we define $\mathrm{E}_{\text {loss }}=1.23 / \mathrm{V}_{\mathrm{oc}}$ and $\mathrm{E}_{\mathrm{com}}=\mathrm{PCE} / \mathrm{FF}$, and equation (4a) can be expressed as: $\eta=E_{\text {loss. }} E_{\text {com }}$

Thus, equation (4a) shows that the efficiency of the PV-EWS system can be estimated using the basic cell parameters, i.e., $\mathrm{V}_{\mathrm{oc}}, \mathrm{FF}$, and PCE, of the PV device. Consequently, we estimated the STH conversion performance of some standard III-V and Si-based multijunction configurations based on their confirmed cell parameters [28, 30-35], as shown in Table 3. While the Si-based triple-junction configuration exhibited a low STH conversion efficiency of 12.2\%, the Si double junction structure exhibited a higher STH efficiency of $16.58 \%$. However, despite gaining higher STH efficiency, the $\mathrm{V}_{\text {oc }}$ of the Si double structure was as low as $1.342 \mathrm{~V}$, which is below the practical photo-voltage requirement $(\geq 1.5 \mathrm{~V})$ for a commercial PV-electrolysis device [16, 29] and hence, insufficient for practical PV-ECP systems. To overcome this issue, some authors proposed the use of a DC/DC converter with a maximum power point tracker [36-39]. However, this complicated the design, increased power loss, and as a result, involved extra cost [36]. Nevertheless, it is possible to obtain a high STH conversion of over 17\% via coupling with III-V multijunction configurations, owing to their high $\mathrm{V}_{\text {oc }}$ of over 1.5 V. Moreover, the III-V double junction devices seemed to generate a slightly higher STH efficiency than that of the III-V triple configurations, although the latter exhibit a higher PCE than that of the former. In equation (4b), $\eta$ depends on two parameters: $E_{\text {loss }}$ and $E_{\text {com, }}$ where $E_{\text {loss }}$ and $E_{\text {com }}$ represent the efficiency loss and 
compensation, respectively. While $\mathrm{E}_{\text {loss }}$ can result from a high applied voltage, $\mathrm{E}_{\mathrm{com}}$ results from the high PCE of a PV device. Therefore, a high $\eta$ value mainly depends on the tradeoff between $\mathrm{E}_{\text {loss }}$ and $\mathrm{E}_{\mathrm{com}}$. Moreover, the lower $\mathrm{V}_{\text {oc }}$ in the III-V double junction PV devices results in lower $E_{\text {loss }}$ than the III-V triple-junction devices: The good tradeoff between $\mathrm{E}_{\text {loss }}$ and $\mathrm{E}_{\mathrm{com}}$ results in a slightly higher $\eta$ value for the III-V double junction devices than the III-V triple devices. This indicates that the manufacture of the III-V double junction configuration is more cost-effective than the III-V triple structure. This is because the former manufacture process involves a larger amount of, and more complex material than that of the latter.

Under practical operation conditions, it is difficult for a PV-EWS system to operate at the $\mathrm{V}_{\mathrm{oc}}$ of the PV device, and therefore, it should be controlled to operate at a maximum power point $\left(\mathrm{P}_{\mathrm{MPP}}\right)$ of the PV devices [40]. Considering the following equation for the fill factor: $\mathrm{FF}=\left(\mathrm{J}_{\mathrm{MPP}}\right.$. $\left.\mathrm{V}_{\mathrm{MPP}}\right) /\left(\mathrm{J}_{\mathrm{sc}} . \mathrm{V}_{\mathrm{oc}}\right)$, where $\mathrm{J}_{\mathrm{MPP}}$ is the short-circuit current density at the maximum power point, equation (3) can be rewritten as follows:

$\eta=\left(1.23 \mathrm{~V} . \mathrm{J}_{\mathrm{WS}} . \eta_{\mathrm{FE}} . \mathrm{PCE}\right) /\left(\mathrm{J}_{\mathrm{MPP}} . \mathrm{V}_{\mathrm{MPP}}\right)$

Considering the same ideal operation conditions as previously mentioned, the value of $\mathrm{J}_{\mathrm{Ws}}$ in this case is nearly equal to $\mathrm{J}_{\mathrm{MPP}}$, and hence, equation (5) can be simplified as follows:

$\eta=(1.23 \mathrm{~V} . \mathrm{PCE}) /\left(\mathrm{V}_{\mathrm{MPP}}\right)$

Thus, equation (6) shows that the essential efficiency loss of a PV-EWS system is due to a VMPP value that is significantly higher than the thermodynamic potential $(1.23 \mathrm{~V})$ of the system, while the PCE can compensate for this loss. Therefore, we implemented multijunction PV devices and used equation (6) to estimate the PV-EWS performance. Figure 1 shows the cross-section schematics of the multijunction devices including a-Si/nc-Si double junction, a-Si/SHJ double 
junction, GaInP/GaAs double junction, and $\mathrm{GaInP} / \mathrm{GaAs} / \mathrm{Ge}$ triple-junction devices. The $\mathrm{J}-\mathrm{V}$ curve characteristics of these devices along with their maximum power points $\left(\mathrm{P}_{\mathrm{MPP}}\right)$ are illustrated in Fig. 2, and the device parameters and STH efficiency are shown in Table 4. In the a-Si/nc-Si double junction device, a $\mathrm{V}_{\mathrm{MMP}}$ as low as $1.1 \mathrm{~V}$ is apparently insufficient for the EWS voltage requirement although its estimated STH efficiency is $12.6 \%$. While the a-Si top cell exhibits a high $\mathrm{V}_{\mathrm{oc}}$ of approximately $1 \mathrm{~V}$, the low $\mathrm{V}_{\mathrm{oc}}$ (normally $<0.6 \mathrm{~V}$ ) of the nc-Si bottom cells remains a drawback for the total $\mathrm{V}_{\mathrm{oc}}$ in this device. Therefore, a total $\mathrm{V}_{\mathrm{oc}}$ enhancement can be affected by the SHJ bottom cell, which can currently reach a high $\mathrm{V}_{\text {oc }}$ of over $0.7 \mathrm{~V}$, resulting in a total $\mathrm{V}_{\text {oc }}$ of 1.61 V. However, the a-Si/SHJ device exhibits a low $\mathrm{J}_{\mathrm{sc}}$ of $9.6 \mathrm{~mA} / \mathrm{cm}^{2}$, resulting in a low PCE of 11.2\%; such low PCE can insignificantly compensate the $\mathrm{E}_{\text {loss }}$ and result in a low STH performance of $7.37 \%$. It is noteworthy that the high efficiency of $14.3 \%$ derive from III-V double junction device. In addition, the III-V double junction device exhibits higher STH performance than that of III-V triple junction device. Furthermore, considering the commercial manufacture cost, the III-V double junction device is apparently more cost effective than the III-V triple device for a PV-EWS system.

The above results emphasize the need for strategies to improve the efficiency of PV-EWS systems using a more cost-effective III-V double junction technology. Besides, equation (6) shows that the STH efficiency of the PV-EWS system can be significantly enhanced by improving the PCE of a III-V double junction device while maintaining a nearly constant voltage. This can be fulfilled by a current state-of-the-art concentrator photovoltaics (CPV) technology, which illuminates a small area of the PV device with very highly concentrated suns; this is one of the most promising solar technologies that is low-cost and highly efficient [41]. The Fraunhofer Institute for Solar Energy Systems has developed the FLATCON ${ }^{\circledR}$ concentrator system [42], which 
is expected to be cost-competitive to the silicon PV technology in certain applications [43]. Although the FLATCON ${ }^{\circledR}$ concentrator tandem solar cells can produce a sufficient $\mathrm{V}_{\text {oc }}>2 \mathrm{~V}$ and high PCE efficiency for the PV-EWS systems [23], it is also important to consider a simple and inexpensive PV-EWS system for a real solution to STH production. The III-V multijunction devices are conventionally grown like-epitaxy on GaAs or Ge bulk substrates: the current stateof-the-art epitaxial lift-off (ELO) technology can release III-V multijunction thin film solar cells out of the underlying GaAs or Ge expensive bulk substrates and transfer the cells to diverse inexpensive substrate types such as a possible thin film, flexible plastic, glass, or metal substrate. For example, Sharp Corporation reported a $29.4 \%$ efficiency with a III-V double junction on a flexible metal film using the ELO technology [44, 45]. Furthermore, an ultralight flexible III-V double junction device on plastic with high efficiency ( $\geq 28 \%$ ) using a novel layer transfer technique has been reported [46]. These reports demonstrate that the ELO technology has the potential to reduce material cost and achieve high efficiency without significantly affecting the cell operation. In addition, the use of the ELO technique can directly attract the monolithic integration of the III-V double junction cell on PEC system to yield a simple, inexpensive, and high-efficiency STH production system [14, 23]. The overall cost of a PV-EWS system for STH production depends on the cost of many different factors such as the material cost, manufacture process, installations, work effort, transportation, and maintenance. Many reports have predicted the targeted $\mathrm{H}_{2}$ cost for STH production: for example, the European Commission anticipates a cost of $3 € \mathrm{~kg}^{-1}$ by 2030, while the US Department of Energy anticipates $4 \$ \mathrm{~kg}^{-1}$ by 2020 [47]. The value in range of $2-4 \$ \mathrm{~kg}^{-1}$ is attributed to the possibly competitive to traditional $\mathrm{H}_{2}$ production from fossil fuels [47]. However, a thorough estimation of the final prices for STH production of a persistently developing PV-EWS system is both difficult and unreliable. Nakamura et al. [20], 
who reported the $24.4 \%$ efficiency of the PV-EWS system, suggested that the PV-EWS system is one of the most realistic methods for future renewable STH production. Moreover, although the practical efficiency of a PV-EWS system remains debatable, PV-EWS systems using III-V double junction devices hold promise as a simple, inexpensive, and highly efficient system.

\section{Conclusion}

We estimated and compared STH the conversion efficiency of a PV-EWS system by coupling various multijunction PV devices with an EWS system: The multijunction PV devices included a III-V double, III-V triple-junction, and Si-based multijunction solar cells. The results showed that the a-Si/nc-Si and a-Si/SHJ double junction PV devices exhibited lower efficiency, while high efficiency was achieved using the III-V double and triple-junction PV devices. Especially, we demonstrated that the PV-EWS system using the III-V double junction solar cells exhibited higher STH conversion performance than that of III-V triple-junction devices. Furthermore, the III-V double junction PV devices required a simpler and inexpensive manufacture technique than the triple junction devices. These results demonstrate that III-V double junction can be used as an alternative for the III-V triple-junction PV devices for highefficiency and low-cost PV-EWS systems. Practically, with the persistent development of the state-of-the-art concentrate PV and ELO technologies, there is great potential for further improving the efficiency and cost-effectiveness of the PV-EWS systems for STH production, which can be competitive to the traditional $\mathrm{H}_{2}$ production from fossil fuels in the future. 


\section{Funding Statement}

This work was supported by the New and Renewable Energy Core Technology Program of the Korea Institute of Energy Technology Evaluation and Planning (KETEP), granted financial resource from the Ministry of Trade, Industry and Energy, Republic of Korea. 


\section{Conflict of Interest}

The authors declare that they have no known competing financial interests or personal relationships that could have appeared to influence the work reported in this paper.

$\square$ The authors declare the following financial interests/personal relationships which may be considered as potential competing interests:

Declarations of interest: None 


\section{Author contributions}

\section{Author 1: Duy Phong Pham}

1. Conceived and designed the analysis

2. Collected the data

3. Performed the analysis

4. Wrote the paper

Author 2: Sunhwa Lee

1. Contributed data or analysis tools

\section{Author 3: Junsin Yi}

1. Conceived and designed the analysis

2. Collected the data

3. Performed the analysis

4. Scientific discussions 
Availability of data and material

Not applicable 


\section{Compliance with ethical standards}

We confirm that all authors consent to ethical standards.

Best Regards.

Authors. 


\section{Consent to participate}

We confirm that all authors consent to participation.

Best Regards.

Authors. 


\section{Consent for Publication}

We confirm that all authors consent to publication.

Best Regards.

Authors. 


\section{Reference}

[1] F.E. Osterloh, Inorganic nanostructures for photoelectrochemical and photocatalytic water splitting, Chemical Society reviews 42(6) (2013) 2294-320.

[2] S. Koumi Ngoh, D. Njomo, An overview of hydrogen gas production from solar energy, Renewable and Sustainable Energy Reviews 16(9) (2012) 6782-6792.

[3] S. Okamoto, M. Deguchi, S. Yotsuhashi, Modulated III-V Triple-Junction Solar Cell Wireless Device for Efficient Water Splitting, The Journal of Physical Chemistry C 121(3) (2017) 13931398.

[4] J. Qi, W. Zhang, R. Cao, Solar-to-Hydrogen Energy Conversion Based on Water Splitting, Advanced Energy Materials 8(5) (2018) 1701620.

[5] M. Ruth, F. Joseck, Hydrogen Threshold Cost Calculation, United States Department of Energy (2011).

[6] E. Miller, C. Ainscough, A. Talapatra, Hydrogen Production Status 2006-2013, United States Department of Energy (2014).

[7] Z. Yin, R. Fan, G. Huang, M. Shen, $11.5 \%$ efficiency of TiO2 protected and Pt catalyzed $\mathrm{n}(+) \mathrm{np}(+)-\mathrm{Si}$ photocathodes for photoelectrochemical water splitting: manipulating the Pt distribution and Pt/Si contact, Chemical communications 54(5) (2018) 543-546.

[8] M.G. Kast, L.J. Enman, N.J. Gurnon, A. Nadarajah, S.W. Boettcher, Solution-deposited $\mathrm{F}: \mathrm{SnO}(2) / \mathrm{TiO}(2)$ as a base-stable protective layer and antireflective coating for microtextured buried-junction H(2)-evolving Si photocathodes, ACS applied materials \& interfaces 6(24) (2014) 22830-7. 
[9] R. Fan, W. Dong, L. Fang, F. Zheng, M. Shen, More than 10\% efficiency and one-week stability of Si photocathodes for water splitting by manipulating the loading of the Pt catalyst and TiO2 protective layer, Journal of Materials Chemistry A 5(35) (2017) 18744-18751.

[10] S. Vanka, E. Arca, S. Cheng, K. Sun, G.A. Botton, G. Teeter, Z. Mi, High Efficiency Si Photocathode Protected by Multifunctional GaN Nanostructures, Nano letters 18(10) (2018) 65306537.

[11] W. Vijselaar, R.M. Tiggelaar, H. Gardeniers, J. Huskens, Efficient and Stable Silicon Microwire Photocathodes with a Nickel Silicide Interlayer for Operation in Strongly Alkaline Solutions, ACS energy letters 3(5) (2018) 1086-1092.

[12] S.W. Boettcher, E.L. Warren, M.C. Putnam, E.A. Santori, D. Turner-Evans, M.D. Kelzenberg, M.G. Walter, J.R. McKone, B.S. Brunschwig, H.A. Atwater, N.S. Lewis, Photoelectrochemical hydrogen evolution using Si microwire arrays, Journal of the American Chemical Society 133(5) (2011) 1216-9.

[13] F. Ronglei, T. Chengshuang, X. Yu, S. Xiaodong, W. Xiaodong, S. Mingrong, Surface passivation and protection of Pt loaded multicrystalline $\mathrm{pn}^{+}$silicon photocathodes by atmospheric plasma oxidation for improved solar water splitting, Applied Physics Letters 109 (2016) 233901. [14] E. Verlage, S. Hu, R. Liu, R.J.R. Jones, K. Sun, C. Xiang, N.S. Lewis, H.A. Atwater, A monolithically integrated, intrinsically safe, $10 \%$ efficient, solar-driven water-splitting system based on active, stable earth-abundant electrocatalysts in conjunction with tandem III-V light absorbers protected by amorphous TiO2 films, Energy \& Environmental Science 8(11) (2015) 3166-3172.

[15] G. H. Lin, M. Kapur, R. C. Kainthla, J. O. M. Bockris, One step method to produce hydrogen by a triple stack amorphous silicon solar cell, Applied Physics Letters 55 (1989) 386. 
[16] J. Luo, J-H. Im, M. T. Mayer, M. Schreier, M. K. Nazeeruddin, N-G. Park, S. D. Tilley, H. J. Fan, M. Gratzel, Water photolysis at $12.3 \%$ efficiency via perovskite photovoltaics and Earthabundant catalysts, Science 345(6204) (2014) 1593-1596.

[17] F. Urbain, V. Smirnov, J.-P. Becker, U. Rau, F. Finger, J. Ziegler, B. Kaiser, W. Jaegermann,

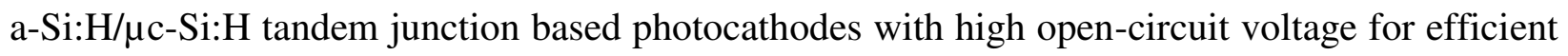
hydrogen production, Journal of Materials Research 29(22) (2014) 2605-2614.

[18] R. Vasudevan, Z. Thanawala, L. Han, T. Buijs, H. Tan, D. Deligiannis, P. Perez-Rodriguez, I.A. Digdaya, W.A. Smith, M. Zeman, A.H.M. Smets, A thin-film silicon/silicon hetero-junction hybrid solar cell for photoelectrochemical water-reduction applications, Solar Energy Materials and Solar Cells 150 (2016) 82-87.

[19] J. Jia, L.C. Seitz, J.D. Benck, Y. Huo, Y. Chen, J.W. Ng, T. Bilir, J.S. Harris, T.F. Jaramillo, Solar water splitting by photovoltaic-electrolysis with a solar-to-hydrogen efficiency over 30, Nature communications 7 (2016) 13237.

[20] A. Nakamura, Y. Ota, K. Koike, Y. Hidaka, K. Nishioka, M. Sugiyama, K. Fujii, A 24.4\% solar to hydrogen energy conversion efficiency by combining concentrator photovoltaic modules and electrochemical cells, Applied Physics Express 8(10) (2015) 107101.

[21] S.A. Bonke, M. Wiechen, D.R. MacFarlane, L. Spiccia, Renewable fuels from concentrated solar power: towards practical artificial photosynthesis, Energy \& Environmental Science 8(9) (2015) 2791-2796.

[22] S. Licht, B. Wang, S. Mukerji, Efficient solar water splitting, exemplified by $\mathrm{RuO}_{2}-\mathrm{Catalyzed}$ AlGaAs/Si Photoelectrolysis, The journal of physical chemistry B 104 (2000) 8920-8924. 
[23] G. Peharz, F. Dimroth, U. Wittstadt, Solar hydrogen production by water splitting with a conversion efficiency of 18\%, International Journal of Hydrogen Energy 32(15) (2007) 32483252.

[24] P. Perez-Rodriguez, W. Vijselaar, J. Huskens, M. Stam, M. Falkenberg, M. Zeman, W. Smith, A.H.M. Smets, Designing a hybrid thin-film/wafer silicon triple photovoltaic junction for solar water splitting, Progress in Photovoltaics: Research and Applications 27(3) (2019) 245-254.

[25] W.J. Chang, K.H. Lee, H. Ha, K. Jin, G. Kim, S.T. Hwang, H.M. Lee, S.W. Ahn, W. Yoon, H. Seo, J.S. Hong, Y.K. Go, J.I. Ha, K.T. Nam, Design Principle and Loss Engineering for Photovoltaic-Electrolysis Cell System, ACS omega 2(3) (2017) 1009-1018.

[26] J.W. Ager, M.R. Shaner, K.A. Walczak, I.D. Sharp, S. Ardo, Experimental demonstrations of spontaneous, solar-driven photoelectrochemical water splitting, Energy \& Environmental Science 8(10) (2015) 2811-2824.

[27] O. Khaselev, J. A. Turner, A monolithic photovoltaic-photoelectrochemical device for hydrogen production via water splitting, Science 280 (1998) 425-427.

[28] M.A. Green, E.D. Dunlop, D.H. Levi, J. Hohl-Ebinger, M. Yoshita, A.W.Y. Ho-Baillie, Solar cell efficiency tables (version 54), Progress in Photovoltaics: Research and Applications 27(7) (2019) 565-575.

[29] H. Dotan, N. Mathews, T. Hisatomi, M. Gratzel, A. Rothschild, On the Solar to Hydrogen Conversion Efficiency of Photoelectrodes for Water Splitting, The journal of physical chemistry letters 5(19) (2014) 3330-4.

[30] K.A. Bertness, S.R. Kurtz, D.J. Friedman, A.E. Kibbler, C. Kramer, J.M. Olson, 29.5\%efficient GaInP/GaAs tandem solar cells, Applied Physics Letters 65(8) (1994) 989-991. 
[31] M.A. Green, K. Emery, Y. Hishikawa, W. Warta, Solar cell efficiency tables (version 35), Progress in Photovoltaics: Research and Applications 18(2) (2010) 144-150.

[32] S. Essig, C. Allebé, T. Remo, J.F. Geisz, M.A. Steiner, K. Horowitz, L. Barraud, J.S. Ward, M. Schnabel, A. Descoeudres, David L. Young, M. Woodhouse, M. Despeisse, C. Ballif, A. Tamboli, Raising the one-sun conversion efficiency of III-V/Si solar cells to $32.8 \%$ for two junctions and 35.9\% for three junctions, Nature Energy 2(9) (2017).

[33] R. Cariou, J. Benick, F. Feldmann, O. Höhn, H. Hauser, P. Beutel, N. Razek, M. Wimplinger, B. Bläsi, D. Lackner, M. Hermle, G. Siefer, S.W. Glunz, A.W. Bett, F. Dimroth, III-V-on-silicon solar cells reaching $33 \%$ photoconversion efficiency in two-terminal configuration, Nature Energy 3(4) (2018) 326-333.

[34] M.A. Green, K. Emery, Y. Hishikawa, W. Warta, Solar cell efficiency tables (version 36), Progress in Photovoltaics: Research and Applications 18(5) (2010) 346-352.

[35] M.W. Wanlass, S. P. Ahrenkiel, R.K. Ahrenkiel, D.S. Albin, J.J. Carapella, A. Duda, J.F. Geisz, S. Kurtz, T. Moriarty, R.J. Wehrer, B. Wernsman, Lattice-mismatched approaches for highperformance, III-V photovoltaic energy converters, Proc. 31st IEEE PVSC, Lake Buena Vista, FL, 1/3-7/05, IEEE Catalog No. 05CH37608C, ISBN: 0-7803-8708-2.

[36] R. García-Valverde, N. Espinosa, A. Urbina, Optimized method for photovoltaic-water electrolyser direct coupling, International Journal of Hydrogen Energy 36(17) (2011) 1057410586.

[37] T.L. Gibson, N.A. Kelly, Predicting efficiency of solar powered hydrogen generation using photovoltaic-electrolysis devices, International Journal of Hydrogen Energy 35(3) (2010) 900911. 
[38] H. Solmecke, O. Just, D. Hackstein, Comparison of solar hydrogen storage systems with and without power-electronic DC-DC converters, Renewable Energy 19 (2000) 333-338.

[39] R. Garciavalverde, C. Miguel, R. Martinezbejar, A. Urbina, Optimized photovoltaic generator-water electrolyser coupling through a controlled DC-DC converter, International Journal of Hydrogen Energy 33(20) (2008) 5352-5362.

[40] L. Arriaga, W. Martinez, U. Cano, H. Blud, Direct coupling of a solar-hydrogen system in Mexico, International Journal of Hydrogen Energy 32(13) (2007) 2247-2252.

[41] P. Huo, I. Lombardero, I. García, I. Rey-Stolle, Enhanced performance of GaInP/GaAs/Ge solar cells under high concentration through $\mathrm{Pd} / \mathrm{Ge} / \mathrm{Ti} / \mathrm{Pd} / \mathrm{Al}$ grid metallization, Progress in Photovoltaics: Research and Applications 27(9) (2019) 789-797.

[42] A.W. Bett, C. Baur, F. Dimroth, G. Lange, M. Meusel, S. van Riesen, G. Siefer, FLATCON ${ }^{\mathrm{TM}}$-MODULES: TECHNOLOGY AND CHARACTERISATION, $3^{\text {rd }}$ World Conference on Photovoltaic Energy Conversion, 2003.

[43] H. Lerchenmuller, A. W. Bett, J. Jaus, G. Willeke, Cost and market perspectives for FLATCON $^{\circledR}$-system, $3^{\text {rd }}$ conference solar concentrator for electricity or hydrogen, 2005.

[44] Q. Lin, H. Huang, Y. Jing, H. Fu, P. Chang, D. Li, Y. Yao, Z. Fan, Flexible photovoltaic technologies, Journal of Materials Chemistry C 2(7) (2014) 1233.

[45] T. Takamoto, M. Kaneiwa, M. Imaizumi, M. Yamaguchi, InGaP/GaAs-based multijunction solar cells, Progress in Photovoltaics: Research and Applications 13(6) (2005) 495-511.

[46] D. Shahrjerdi, S.W. Bedell, C. Bayram, C.C. Lubguban, K. Fogel, P. Lauro, J.A. Ott, M. Hopstaken, M. Gayness, D. Sadana, Ultralight High-Efficiency Flexible InGaP/(In)GaAs Tandem Solar Cells on Plastic, Advanced Energy Materials 3(5) (2013) 566-571. 
[47] J. Rongé, T. Bosserez, L. Huguenin, M. Dumortier, S. Haussener, J.A. Martens, Solar Hydrogen Reaching Maturity, Oil \& Gas Science and Technology - Revue d'IFP Energies nouvelles 70(5) (2015) 863-876. 


\section{Table and Figure Captains}

Table 1. Recent best STH efficiencies of PEC systems based on Si-based photocathodes.

Table 2. Recent impressive STH efficiencies of PV-EWS systems using multijunction PV devices.

Table 3. STH efficiency estimation of an EWS system via coupling with the world-record multijunction solar cell results.

Table 4. STH efficiency estimation of an EWS system via coupling with our experimental multijunction cell results.

Fig. 1. Cross-section schematics of the multijunction solar cells including: a) a-Si/nc-Si double junction; b) a-Si/SHJ double junction; c) GaInP/GaAs double junction; and d) GaInP/GaAs/Ge triple-junction cells.

Fig. 2. Light J-V curves of multijunction solar cells with maximum power point $\left(\mathrm{P}_{\mathrm{MPP}}\right)$. 
Table 1. Recent best STH efficiencies of PEC systems based on Si-based photocathodes.

\begin{tabular}{|c|c|c|c|}
\hline Photocathode structure & Group/institute & Years & STH efficiency (\%) \\
\hline $\mathrm{TiO}_{2} / \mathrm{Pt}$ nanoparticles $/ \mathrm{n}^{+} \mathrm{np}^{+}-\mathrm{Si}$ & Z. Yin et al. [7] & 2018 & 11.5 \\
\hline $\mathrm{Ir} / \mathrm{TiO}_{2} / \mathrm{FTO} / \mathrm{n}^{+} \mathrm{p}-\mathrm{Si}$ & M. G. Kast et al. [8] & 2014 & 10.9 \\
\hline $\mathrm{TiO}_{2} / \mathrm{Pt}$ nanoparticles/n ${ }^{+} \mathrm{p}-\mathrm{Si}$ & R. Fan et al. [9] & 2017 & 10.5 \\
\hline Pt nanoparticles $/ \mathrm{n}^{+}-\mathrm{GaN}$ nanowire $/ \mathrm{n}^{+} \mathrm{p}-\mathrm{Si}$ & S. Vanka et al. [10] & 2018 & 10.5 \\
\hline NiMo/NiSi/n+p-Si microwire array & W. Vijselaar et al. [11] & 2018 & 10.1 \\
\hline Pt nanoparticles $/ n^{+} \mathrm{p}-\mathrm{Si}$ planar & S. W. Boettcher et al. [12] & 2011 & 9.6 \\
\hline $\mathrm{Pt} @ \mathrm{SiO}_{2} / \mathrm{n}^{+} \mathrm{p}-\mathrm{Si}$ & R. Fan et al. [13] & 2016 & 8.9 \\
\hline
\end{tabular}


Table 2. Recent impressive STH efficiencies of PV-EWS system using multijunction PV devices.

\begin{tabular}{|c|c|c|c|c|}
\hline Group/institute & PV device & Photoelectrodes & Years & $\begin{array}{l}\text { STH } \\
\text { efficiency }(\%)\end{array}$ \\
\hline J. Jieyang et al. [19] & InGaP/GaAs/GaInNAsSb & $\begin{array}{l}\text { PEM electrolyers; } \\
\text { Pt }_{\text {black (cathode) and }} \\
\mathrm{Ir}_{\text {black }} \text { (anode) }\end{array}$ & 2016 & 30 \\
\hline N. Akihiro et al. [20] & $\mathrm{InGaP} / \mathrm{GaAs} / \mathrm{Ge}$ & $\begin{array}{l}\text { polymer-electrolyte EC } \\
\text { cells; Pt-loaded carbon } \\
\text { paper electrodes; wired }\end{array}$ & 2015 & 24.4 \\
\hline B.A. Shannon et al. [21] & $\mathrm{GaInP} / \mathrm{GaAs} / \mathrm{Ge}$ & $\mathrm{Ni}$ foam electrodes & 2015 & 22.4 \\
\hline S. Licht et al. [22] & $\mathrm{AlGaAs} / \mathrm{Si}$ & $\mathrm{RuO}_{2} / \mathrm{Pt}_{\text {black }}$ & 2000 & 18.3 \\
\hline P. Gerhard et al. [23] & GaInP/GaInAs & $\begin{array}{l}\mathrm{PEM} / \mathrm{Pt} \text { cathode/Ir } \\
\text { anode }\end{array}$ & 2007 & 18 \\
\hline L. Jingshan et al. [16] & perovskite tandem & $\begin{array}{l}\text { NiFe electrode; } \\
\text { alkaline electrolyte }\end{array}$ & 2014 & 12.3 \\
\hline V. Ravi et al. [18] & nc-Si:H/SHJ & a-SiC photocathode & 2016 & 10.4 \\
\hline P-R. Paula et al. [24] & a-Si:H (TF)/nc-Si:H (TF)/c-Si (W) & $\mathrm{IrO}_{\mathrm{x}} / \mathrm{Pt}$ & 2018 & 8.3 \\
\hline
\end{tabular}


Table 3. STH efficiency estimation of an EWS system via coupling with the world-record multijunction solar cell results.

\begin{tabular}{|c|c|c|c|c|c|c|}
\hline Classification & Group/Institute & $\begin{array}{l}\mathrm{V}_{\mathrm{oc}} \\
(\mathrm{V})\end{array}$ & $\begin{array}{l}\mathbf{J}_{\mathrm{sc}} \\
\left(\mathrm{mA} / \mathrm{cm}^{2}\right)\end{array}$ & $\begin{array}{l}\mathrm{FF} \\
(\%)\end{array}$ & $\begin{array}{l}\mathrm{E}_{\mathrm{ff}} \\
(\%)\end{array}$ & $\begin{array}{l}\text { STH } \\
\text { efficiency } \\
(\%)\end{array}$ \\
\hline \multicolumn{7}{|l|}{ III-V double junction } \\
\hline GaInP/GaAs & LG Electronics [28] & 2.568 & 14.56 & 87.7 & 32.8 & 17.91 \\
\hline GaInP/GaAs & NREL [30] & 2.385 & 14.0 & 88.5 & 29.5 & 17.1 \\
\hline GaInP/GaAs & Japan Energy [31] & 2.488 & 14.22 & 85.6 & 30.3 & 17.49 \\
\hline GaInP/GaAs & S. Essig et al. [32] & 2.52 & 13.61 & 87.5 & 30.0 & 16.73 \\
\hline \multicolumn{7}{|l|}{ III-V triple-junction } \\
\hline GaInP/GaAs/InGaAs & Sharp [28] & 3.065 & 14.27 & 86.7 & 37.9 & 17.54 \\
\hline GaInP/GaAs/Si & R. Carious et al. [33] & 3.127 & 12.7 & 83.8 & 33.3 & 15.63 \\
\hline GaInP/GaAs/GaInAs & M.W. Wanlass et al. [35] & 2.91 & 12.217 & 87.54 & 31.1 & 15.01 \\
\hline $\mathrm{GaInP} / \mathrm{GaAs} / \mathrm{Ge}$ & Spectrolab [34] & 2.622 & 14.37 & 85 & 32.0 & 17.66 \\
\hline \multicolumn{7}{|l|}{ Si-based multijunction } \\
\hline a-Si/nc-Si/nc-Si & AIST [28] & 1.922 & 9.94 & 73.4 & 14.0 & 12.2 \\
\hline $\mathrm{a}-\mathrm{Si} / \mathrm{nc}-\mathrm{Si}$ & AIST [1] & 1.342 & 13.45 & 70.2 & 12.7 & 16.58 \\
\hline
\end{tabular}


Table 4. STH efficiency estimation of an EWS system via coupling with our experimental multijunction cell results.

\begin{tabular}{llllllll}
\hline The multijunction cells & $\begin{array}{l}\mathrm{V}_{\mathrm{oc}} \\
(\mathrm{V})\end{array}$ & $\begin{array}{l}\mathrm{J}_{\mathrm{sc}} \\
\left(\mathrm{mA} / \mathrm{cm}^{2}\right)\end{array}$ & $\begin{array}{l}\mathrm{FF} \\
(\%)\end{array}$ & $\begin{array}{l}\mathrm{E}_{\mathrm{ff}} \\
(\%)\end{array}$ & $\begin{array}{l}\mathrm{V}_{\mathrm{MMP}} \\
(\mathrm{V})\end{array}$ & $\begin{array}{l}\mathrm{J}_{\mathrm{MPP}} \\
\left(\mathrm{mA} / \mathrm{cm}^{2}\right)\end{array}$ & $\begin{array}{l}\mathrm{STH} \\
\text { efficiency }(\%)\end{array}$ \\
\hline \hline GaInP/GaAs & 2.42 & 12.0 & 85.67 & 24.87 & 2.15 & 11.66 & 14.22 \\
GaInP/GaAs/Ge & 2.63 & 11.6 & 84.5 & 25.77 & 2.42 & 10.75 & 13.09 \\
a-Si/nc-Si & 1.39 & 12.3 & 70.4 & 12.1 & 1.18 & 10.27 & 12.61 \\
a-Si/SHJ & 1.61 & 9.6 & 76.2 & 11.7 & 1.4 & 8.39 & 7.37 \\
\hline \hline
\end{tabular}




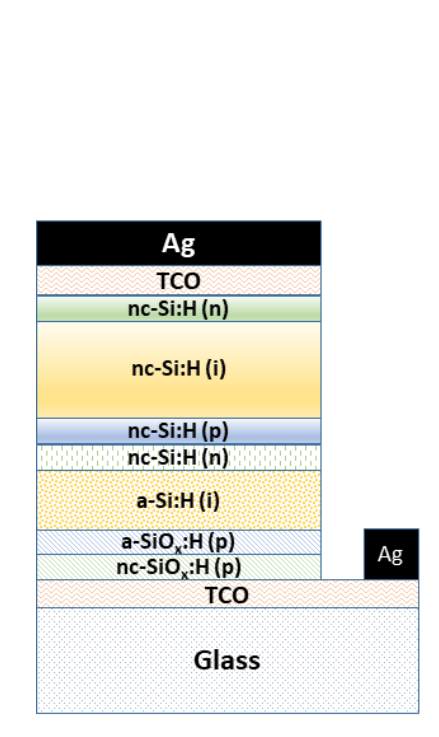

a) a-Si/nc-Si

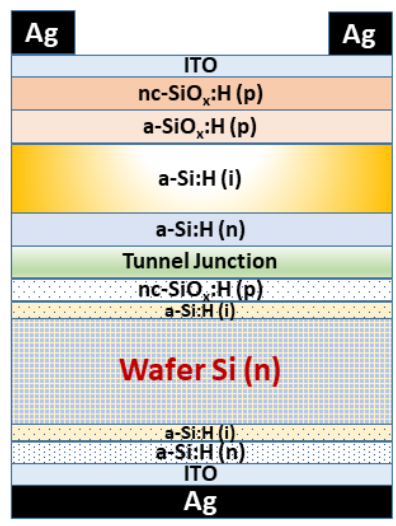

b) a-Si/SHJ

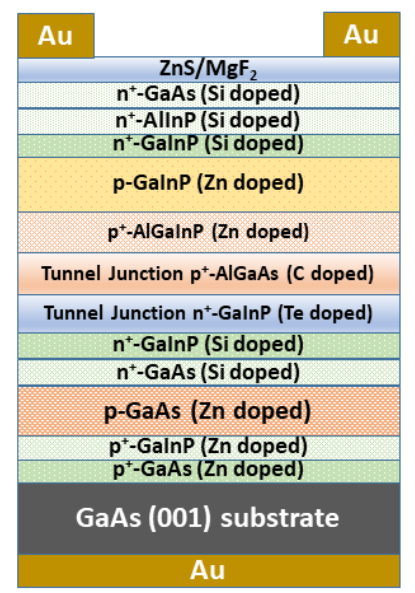

c) GalnP/GaAs

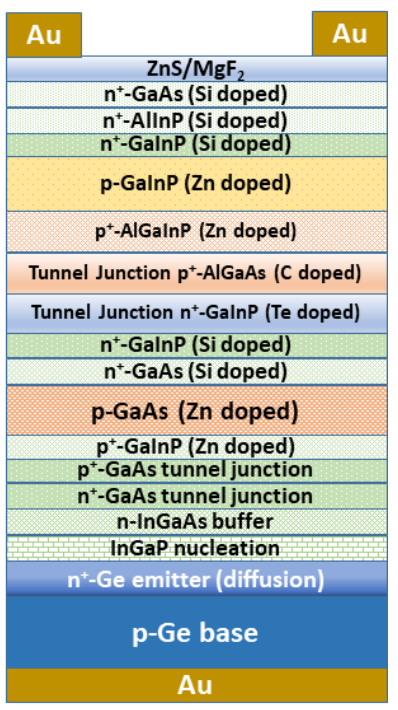

d) GaInP/GaAs/Ge

Fig. 1. Cross-section schematics of the multijunction solar cells including: a) a-Si/nc-Si double junction; b) a-Si/SHJ double junction; c) GaInP/GaAs double junction; and d) GaInP/GaAs/Ge triple-junction cells. 


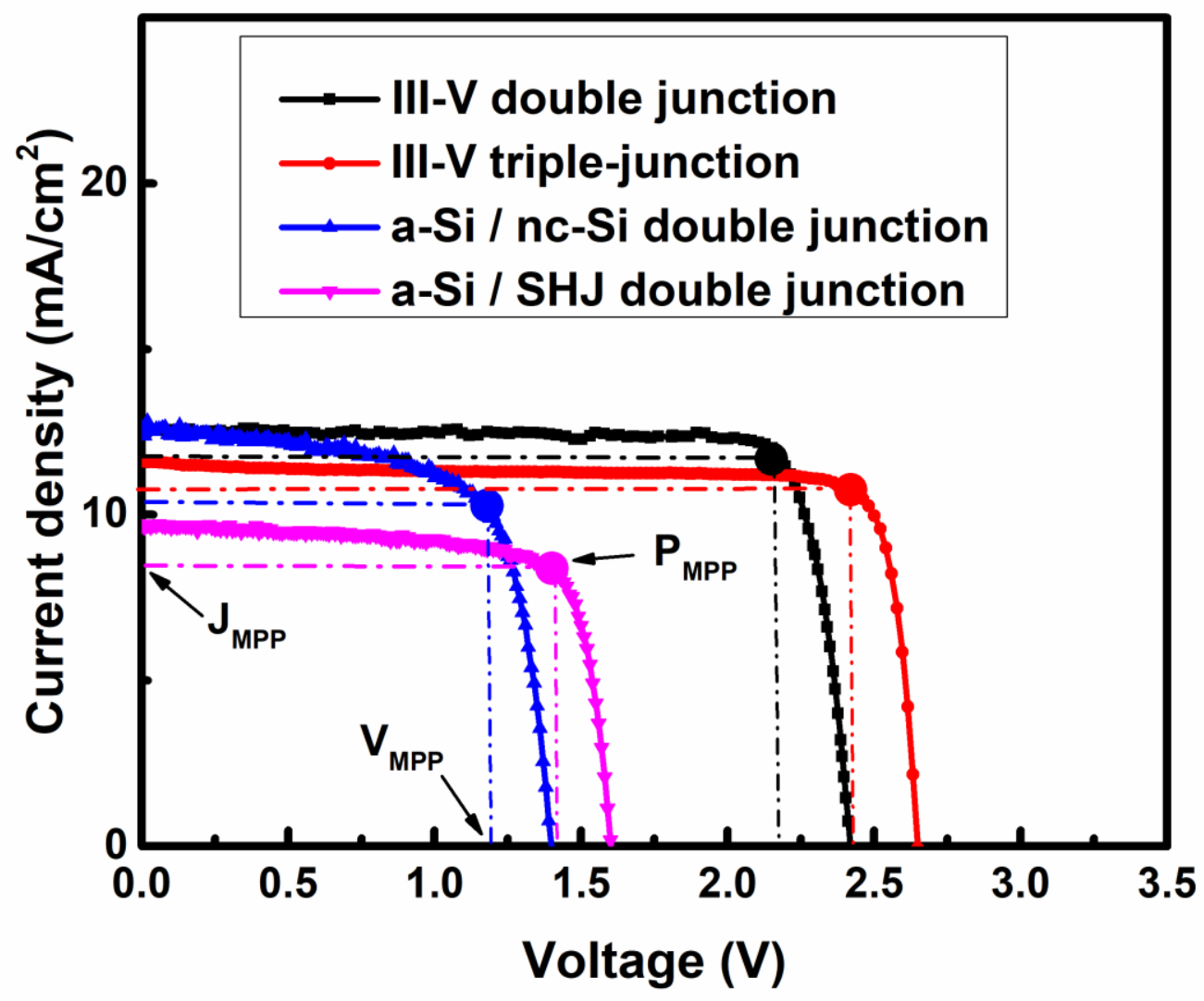

Fig. 2. Light $\mathrm{J}-\mathrm{V}$ curves of multijunction solar cells with maximum power point ( $\left.\mathrm{P}_{\mathrm{MPP}}\right)$. 


\begin{tabular}{|c|}
\hline Ag \\
\hline TCO \\
\hline nc-Si:H (n) \\
\hline nc-Si:H (i) \\
\hline nc-Si:H (p) \\
\hline nc-Si:H (n) \\
\hline$a-S i: H(i)$ \\
\hline$a-S i O_{\mathbf{x}}: H(p)$ \\
\hline nc-SiO $:$ :H (p) \\
\hline TCO \\
\hline Glass \\
\hline \\
\end{tabular}

\section{a) a-Si/nc-Si}

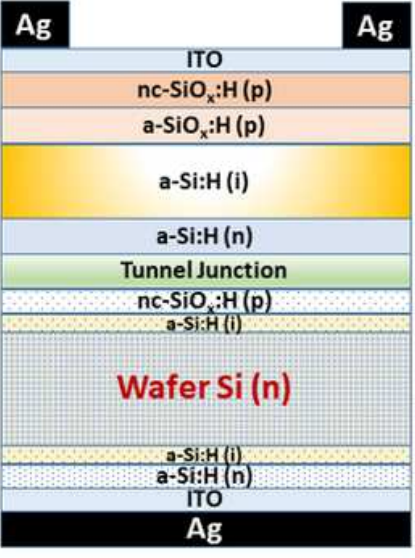

b) a-Si/SHJ

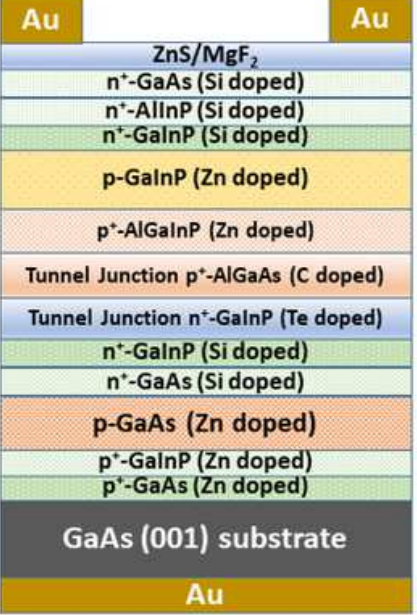

c) GalnP/GaAs

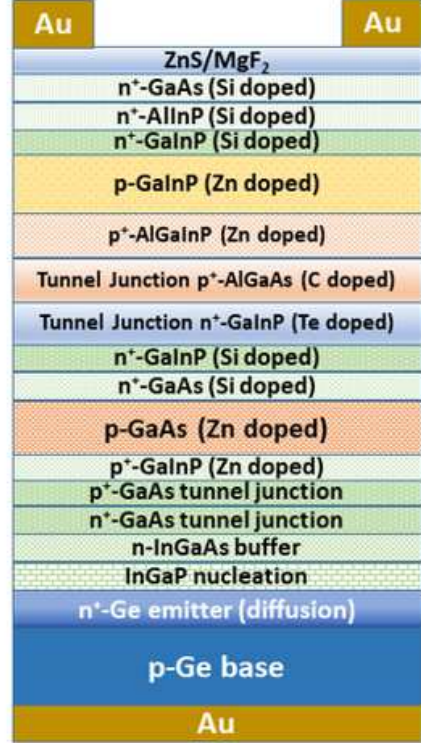

d) GalnP/GaAs/Ge

\section{Figure 1}

Cross-section schematics of the multijunction solar cells including: a) a-Si/nc-Si double junction; b) a$\mathrm{Si} / \mathrm{SHJ}$ double junction; c) GalnP/GaAs double junction; and d) GalnP/GaAs/Ge triple-junction cells. 


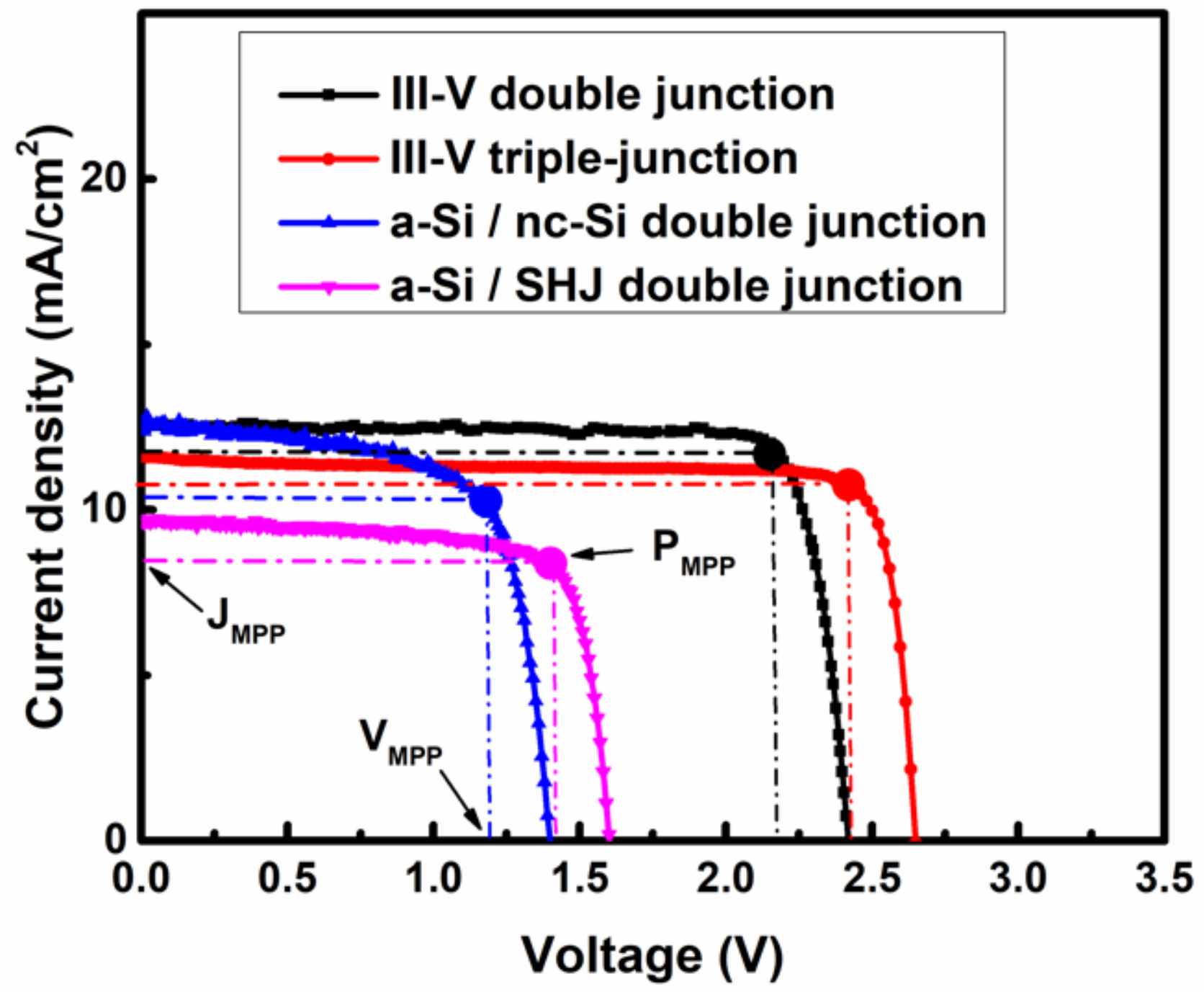

Figure 2

Light $\mathrm{J}-\mathrm{V}$ curves of multijunction solar cells with maximum power point (PMPP). 